\title{
前置補償器をもつ一般化最小分散制御に対する 適応系の一構成
}

\author{
山本透*·石原弘一*·大松繁** \\ A Construction of Adaptive System for Generalized Minimum \\ Variance Control with a Pre-Compensator
}

Toru Yamamoto*, Hirokazu Ishinara* and Sigeru Omatu**

A design of generalized minimum variance controller with a quadratic cost function by Clarke, et al. is a useful method for nonminimum-phase systems. In this method, it is important to consider how to select the parameters in the cost function from viewpoints of stability of the closed-loop system and the steady state offset.

In this paper, first, we note that this system contains a partial feedback compensator of controller in the closed-loop and a precompensator. In this case, both of these compensators have the same design polynomial in these denominator polynomials. Therefore, if we introduce the transfer function of the partial feedback compensator so as to stabilize the closed-loop, it is impossible to increase the freedom of the precompensator. Thus, we construct a generalized minimum variance controller to design these compensators independently. Based on Allidina, et al. 's method, the poles of the closed-loop system have been placed and then the transfer function of the pre-compensator is determined such that the overshoot becomes small and settling-time is short as much as possible. Finally, we illustrate the numerical simulation results to show the effectiveness.

Key Words: adaptive control, self-tuning control, generalized minimum variance control, nonminimum-phase system, compensator

* 高松工業高等専門学校 高松市勅使町 355

** 徳島大学工学部 徳島市南常三島町 2-1

* Takamatsu National College of Technology, Takamatsu

** Faculty of Engineering, University of Tokushima, Tokushima

(Received August 14, 1989)

(Revised January .29, 1990)

\section{1. 緒言}

非最小位相系 ${ }^{1)}$ 亿対する Self-Tuning Control ${ }^{2), 3)}$ (STC) 手法として, Clarke らによる一般化最小分散 適応制御 ${ }^{4), 5)}$ が有効な手法とされている. また, 極配 置に基づく適応制御手法 ${ }^{6) ~ 9) ~}$ も提案され，新中らは， 一般化最小分散適応制御系之適応極配置系との関連に ついてあ報告している(0).さらに，著者らは，一般化 最小分散適応制御における評価規範の一つに対する, 定常誤差解析掞よび規準值追従性の改善アルゴリズム について考察した ${ }^{11), 12)}$. また，圧力制御系への適用 結果 ${ }^{13)}$ 屯報告し，改善アルゴリズムの有効性について 検証している．乙れまで報告されている一般化最小分 散適応制御系に関する考察においては，評価規範に含 まれる重み多項式は，適応極配置を考慮して，閉ルー プ系が安定化されるように設計されている，いいかえ れば，一般化最小分散適応制御系の設計は，制御系の 安定化に主眼が置かれ，制御系の質からの検討はなさ れていない.

本論文では，まず一般化最小分散適応制御系が， Åström らにより構成された最小分散制御方策に基づ く $\mathrm{STC}^{2), 3)}$ に比べ, 局所フィードバック補償器と前置 補償器を挿入した制御系になっているととを示す。こ のとき, 各補償器の伝達関数は, 評価規範に含まれる 重み多項式から構成されていて，制御系の安定性や質 を左右するため，乙れらの設計方法は重要な問題であ る. 本来, 制御系の安定性から局所フィードバック補 償器を設計し, 制御系の質を考慮して, 前置補償器が 設計されるべきである.しかし，従来の一般化最小分 散適応制御系においては，局所フィードバック補償器 の伝達関数の分母多項式之前置補償器の伝達関数の分 母多項式に，共通の重み多項式が含まれるため，安定 化を考慮して局所フィードバック補償器を設計すれ 
ば，前置補償器の設計は，その制約を受け，設計仕様 に近い制御系を構成するととは難しくなる場合があ る. そこで, 新しい重み多項式を導入し, 従来の一般 化最小分散適応制御における評価規範を組み換えるこ とにより, 局所フィードバック補償器と前置補償器の 伝達関数が，独立して設計でき，閉ループ系の安定性 を図った上で, 前置補償器の設計により, 制御系の質 を改善することができる制御系を構成するととが可能 なアルゴリズムを構成する. 最後に, 考察したアルゴ リズムの有効性を検証するため，数值計算を行う.

\section{2. 一般化最小分散適応制御}

不安定零点をあつシステム，すなわち非最小位相系 に対して，Clarke らは，2 次評価規範を最小化する 一般化最小分散適応制御系を構成した ${ }^{4), 5}$. 次章で述 べる本論文の適応制御アルゴリズムとの差異を明確に するために，以下では Clarke らの手法 ${ }^{4), 5}$ そついて 要約する.

まず，対象とするシステムは，次式で定義される非 最小位相系とする。

$$
A\left(z^{-1}\right) y(t)=z^{-k} B\left(z^{-1}\right) u(t)+C\left(z^{-1}\right) \xi(t)
$$

ただし， $A\left(z^{-1}\right)$ および $C\left(z^{-1}\right)$ は，漸近安定な多項式， $B\left(z^{-1}\right)$ は不安定零点をむつ多項式で, それぞれ次式 を満足する多項式である.

$$
\left.\begin{array}{l}
A\left(z^{-1}\right)=1+a_{1} z^{-1}+a_{2} z^{-2}+\cdots+a_{n} z^{-n} \\
B\left(z^{-1}\right)=b_{0}+b_{1} z^{-1}+b_{2} z^{-2}+\cdots+b_{m} z^{-m} \\
C\left(z^{-1}\right)=1+c_{1} z^{-1}+c_{2} z^{-2}+\cdots+c_{l} z^{-l}
\end{array}\right\}
$$

ここで, $y(t), u(t), w(t)$ および $k$ は, シス テムの出力, 制御入力, 規準入力およびむだ 時間とする.また， $\xi(t)$ は外乱を示し，こて では, $E[\xi(t)]=0, E\left[\xi^{2}(t)\right]=\sigma^{2}$ と定義する.

(1)式に示す非最小位相系住対し, Clarke らは，次式により与えられる評価規範を最 小化する一般化最小分散適応制御則を提案し た.

$$
\begin{aligned}
J= & E\left[\left(P\left(z^{-1}\right) y(t+k)-R\left(z^{-1}\right) w(t)\right)^{2}\right. \\
& \left.+\left(Q^{\prime}\left(z^{-1}\right) u(t)\right)^{2}\right]
\end{aligned}
$$

ただし， $P\left(z^{-1}\right), Q\left(z^{-1}\right)$ および $R\left(z^{-1}\right)$ は, 次式を満 足する重み多項式である。

$$
\left.\begin{array}{l}
p\left(z^{-1}\right)=p_{0}+p_{1} z^{-1}+p_{2} z^{-2}+\cdots+p_{n_{1}} z^{-n_{1}} \\
Q^{\prime}\left(z^{-1}\right)=q_{0}^{\prime}+q_{1}^{\prime} z^{-1}+q_{2}^{\prime} z^{-2}+\cdots+q_{n_{2}}^{\prime} z^{-n_{2}} \\
R\left(z^{-1}\right)=r_{0}+r_{1} z^{-1}+r_{2} z^{-2}+\cdots+r_{n_{3}} z^{-n_{3}}
\end{array}\right\}
$$

(1)式に示すシステムに対し，（3)式を最小にする 制御入力は,

$$
\begin{aligned}
& P\left(z^{-1}\right) F\left(z^{-1}\right) y(t)+\left(C\left(z^{-1}\right) Q\left(z^{-1}\right)\right. \\
& \left.\quad+P\left(z^{-1}\right) E\left(z^{-1}\right) B\left(z^{-1}\right)\right) u(t) \\
& \quad-C\left(z^{-1}\right) R\left(z^{-1}\right) w(t)=0
\end{aligned}
$$

を満足する $u(t)$ として与えられる ${ }^{4), 55}$. ここで, $E\left(z^{-1}\right), F\left(z^{-1}\right)$ は，つぎの恒等式を満足する多項式で ある。

$$
\left.\begin{array}{l}
C\left(z^{-1}\right)=A\left(z^{-1}\right) E\left(z^{-1}\right)+z^{-k} F\left(z^{-1}\right) \\
E\left(z^{-1}\right)=1+e_{1} z^{-1}+e_{2} z^{-2}+\cdots+e_{k-1} z^{-(k-1)} \\
F\left(z^{-1}\right)=f_{0}+f_{1} z^{-1}+f_{2} z^{-2}+\cdots+f_{n-1} z^{-(n-1)}
\end{array}\right\}
$$

さらに, $Q\left(z^{-1}\right)$ は,

$$
Q\left(z^{-1}\right) \triangleq \frac{q_{0}^{\prime}}{p_{0} b_{0}} Q^{\prime}\left(z^{-1}\right)
$$

である.このとき，(1)式の最小化は，

$$
\begin{aligned}
\phi(t+k) \triangleq & P\left(z^{-1}\right) y(t+k)+Q\left(z^{-1}\right) u(t) \\
& -R\left(z^{-1}\right) w(t)
\end{aligned}
$$

として定義したとき，一般化出力 $\phi(t+k)$ の最小分散 制御を意味している.

以上で与えられた Clarke らの手法の構造を明確に するために，(1)式および(5)式で与えられる制御系 のブロック線図を Fig. 1 (a ) に示す. また，比較の ために， Åström らによる最小分散制御に基づいた STC のブロック線図を Fig. 1(b)に示す.

Fig. 1 (a)，（b）加ら，乙の一般化最小分散適応 制御系は, 通常の STC と比較して

$$
H_{1}\left(z^{-1}\right)=\frac{C\left(z^{-1}\right) Q\left(z^{-1}\right)}{P\left(z^{-1}\right)}
$$

の局所フィードバック補償器と,

$$
H_{2}\left(z^{-1}\right)=\frac{R\left(z^{-1}\right)}{P\left(z^{-1}\right)}
$$

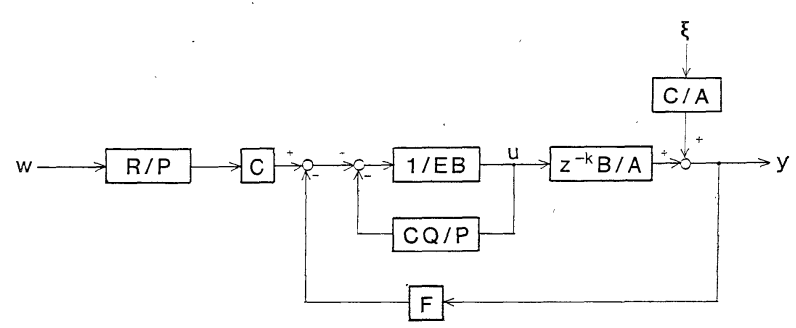

(a) Block diagram of the generalized minimum variance control system

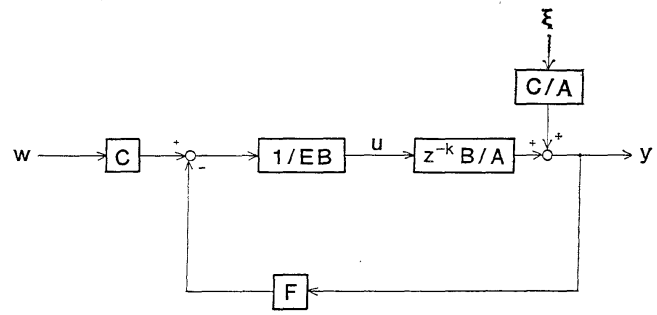

(b) Block diagram of the usual self-tuning control system

Fig. 1 
の前置補償器を挿入した制御系になっていることがわ かる. $P\left(z^{-1}\right), Q\left(z^{-1}\right)$ および $R\left(z^{-1}\right)$ は, 制御系の安 定性や質を左右するため，乙れらの設計は重要な問題 である. Allidina らは, 制御系の特性方程式の根を 安定な範囲内に指定することで， $P\left(z^{-1}\right)$ および $Q\left(z^{-1}\right)$ を設計する方法を提案している ${ }^{8)}$. しかし， $H_{1}\left(z^{-1}\right)$ と $H_{2}\left(z^{-1}\right)$ の分母多項式に, 多項式 $P\left(z^{-1}\right)$ を共通に 含むため, どちらか一方を設計すると, 他方の設計 は，その制約を受ける. したがって，設計仕様に近い 制御系を設計することは難しい. そこで，乙の問題を 改善するために, 局所フィードバック補償器と前置補 償器の伝達関数を個々に設計することができる方法に ついて, 次章で考察する。

\section{3. 前置補償器の設計に基づいた 制御系の構成}

\section{1 新しい制御系の構成}

Fig. 1(a)に示したブロック線図において，前置補 償器の伝達関数の分母多項式の $P\left(z^{-1}\right)$ を，新しい重 み多項式 $S\left(z^{-1}\right)$ 飞書き換え，このときのブロック線 図を Fig. 2 として示す。ただし， $S\left(z^{-1}\right)$ は，

$$
S\left(z^{-1}\right)=s_{0}+s_{1} z^{-1}+s_{2} z^{-2}+\cdots+s_{n_{4}} z^{-n_{4}}
$$

である.とのとき，Fig. 2 から明らかなように，局 所フィードバック補償器は,

$$
H_{1}\left(z^{-1}\right)=\frac{C\left(z^{-1}\right) Q\left(z^{-1}\right)}{P\left(z^{-1}\right)}
$$

前置補償器は,

$$
H_{2}\left(z^{-1}\right)=\frac{R\left(z^{-1}\right)}{S\left(z^{-1}\right)}
$$

となり，閉ループ系の安定化を考慮して，局所フィー ドバック補償器を，さらに制御系の質を考慮して，前 置補償器の伝達関数を，それぞれ独立に設計すること が可能となる.とこで，Fig. 2 に示す制御系は，次 式に示す 2 次評価規範の最小化に基づいている.

$$
\begin{aligned}
J_{1}= & E\left[\left\{P\left(z^{-1}\right)\left(S\left(z^{-1}\right) y(t+k)-R\left(z^{-1}\right) w(t)\right)\right\}^{2}\right. \\
& \left.+\left(S\left(z^{-1}\right) Q^{\prime}\left(z^{-1}\right) u(t)\right)^{2}\right]
\end{aligned}
$$

また，(15)式を最小にする制御入力は，

$$
\begin{aligned}
& P\left(z^{-1}\right) S\left(z^{-1}\right) F\left(z^{-1}\right) y(t)+\left(S\left(z^{-1}\right) C\left(z^{-1}\right) Q\left(z^{-1}\right)\right. \\
& \left.\quad+P\left(z^{-1}\right) S\left(z^{-1}\right) E\left(z^{-1}\right) B\left(z^{-1}\right)\right) u(t) \\
& \quad-P\left(z^{-1}\right) R\left(z^{-1}\right) C\left(z^{-1}\right) w(t)=0
\end{aligned}
$$

を満足する $u(t)$ として与えられる. ここで，（3)式 および (5)式と比較すると，評価規範 $J_{1}$ において， $P\left(z^{-1}\right) \leftarrow P\left(z^{-1}\right) S\left(z^{-1}\right), \quad R\left(z^{-1}\right) \leftarrow P\left(z^{-1}\right) R\left(z^{-1}\right)$ および $Q^{\prime}\left(z^{-1}\right) \leftarrow S\left(z^{-1}\right) Q^{\prime}\left(z^{-1}\right)$ とした特別な場合に等価とな るが， $S\left(z^{-1}\right)$ の導入により $P\left(z^{-1}\right), Q\left(z^{-1}\right), R\left(z^{-1}\right)$ お よび $S\left(z^{-1}\right)$ の意味づけを，ブロック線図により明確 にすることができる。

次節において, 重み多項式 $P\left(z^{-1}\right), Q\left(z^{-1}\right), R\left(z^{-1}\right)$ 招よび $S\left(z^{-1}\right)$ の一設計方法について考察する。

\section{2 重み多項式の設計}

\section{3. $2.1 P\left(z^{-1}\right), Q\left(z^{-1}\right)$ の設計8)}

先に考察したように，乙の一般化最小分散適応制御 系は， Åström らによる最小分散制御に基づく適応制 御系に，局所フィードバック補償器が捕入された型と なっている，実際は，制御系の質を向上させるよう に，乙の局所フィードバック補償器が設計されるべき であるが，乙こでは，対象とするシステムが，非最小 位相系であることから，安定性が保証されるように局 所フィードバック補償器つまり, $P\left(z^{-1}\right), Q\left(z^{-1}\right)$ を。

Allidina ら ${ }^{8)}$ の方法によって設計する.

Fig. 2 に示す閉ループ系の特性方程式は,

$$
T\left(z^{-1}\right) \triangleq P\left(z^{-1}\right) B\left(z^{-1}\right)+Q\left(z^{-1}\right) A\left(z^{-1}\right)
$$

である. 閉ループ系の安定性は， $T\left(z^{-1}\right)=0$ の根の位 置に支配される，したがって，安定となる極つまり $T\left(z^{-1}\right)=0$ の根を指定する.

まず，(17)式から $P\left(z^{-1}\right)$ および $Q\left(z^{-1}\right)$ が一意に 計算できるように，次式のように次数を定義する.

$$
\begin{aligned}
& \operatorname{deg} P\left(z^{-1}\right)=n_{p} \triangleq n-1 \\
& \operatorname{deg} Q\left(z^{-1}\right)=m_{q} \triangleq m-1
\end{aligned}
$$

このとき, $T\left(z^{-1}\right)$ の次数は,

$$
\operatorname{deg} T\left(z^{-1}\right) \leqq n+m-1
$$

となる.ここで,

$$
\begin{aligned}
T\left(z^{-1}\right) \triangleq & \alpha_{0}+\alpha_{1} z^{-1}+\alpha_{2} z^{-2} \div \cdots \\
& +\alpha_{n+m-1} z^{-(n+m-1 ;}
\end{aligned}
$$

と定義して， $\alpha_{0} \sim \alpha_{n+m-1}$ を指定することで， (17) 式より $P\left(z^{-1}\right)$ および $Q\left(z^{-1}\right)$ の各パラ メータを決定する。

\subsection{2 $R\left(z^{-1}\right), S\left(z^{-1}\right)$ の設計}

以下では, 前置補償器の伝達関数 $H_{2}\left(z^{-1}\right)$ における $R\left(z^{-1}\right)$ および $S\left(z^{-1}\right)$ の設計方法 について考察する.

いま，Fig. 2 に示した制御系全体の伝達 
関数 $W\left(z^{-1}\right)$ は,

$$
W\left(z^{-1}\right)=\frac{z^{-k} R\left(z^{-1}\right) P\left(z^{-1}\right) B\left(z^{-1}\right)}{S\left(z^{-1}\right)\left(P\left(z^{-1}\right) B\left(z^{-1}\right)+Q\left(z^{-1}\right) A\left(z^{-1}\right)\right)}
$$

となる. ここで, $R\left(z^{-1}\right)$ と $S\left(z^{-1}\right)$ を次式として定義 する.

$$
R\left(z^{-1}\right)=K\left(P\left(z^{-1}\right) B\left(z^{-1}\right)+Q\left(z^{-1}\right) A\left(z^{-1}\right)\right) R^{\prime}\left(z^{-1}\right)
$$

$$
S\left(z^{-1}\right)=P\left(z^{-1}\right) S^{\prime}\left(z^{-1}\right)
$$

ただし， $R^{\prime}\left(z^{-1}\right)$ 㧍よび $S^{\prime}\left(z^{-1}\right)$ は，

$$
\left.\begin{array}{l}
R^{\prime}\left(z^{-1}\right)=r_{0}^{\prime}+r_{1}^{\prime} z^{-1}+r_{2}^{\prime} z^{-2}+\cdots+r_{n_{3}^{\prime}}^{\prime} z^{-n_{3}^{\prime}} \\
S^{\prime}\left(z^{-1}\right)=s_{0}^{\prime}+s_{1}^{\prime} z^{-1}+s_{2}^{\prime} z^{-2}+\cdots+s_{n_{4}^{\prime}}^{\prime} z^{-n_{4}^{\prime}}
\end{array}\right\}
$$
であり,

$$
\begin{aligned}
& n_{3}^{\prime}=n_{3}-m-n+1 \\
& n_{4}^{\prime}=n_{4}-n+1
\end{aligned}
$$

とする. (23)式および(24)式から，(22)式は,

$$
W\left(z^{-1}\right)=\frac{z^{-k} K R^{\prime}\left(z^{-1}\right) B\left(z^{-1}\right)}{S^{\prime}\left(z^{-1}\right)}
$$

之書き換えられる.したがって， $S^{\prime}\left(z^{-1}\right)$ の設計が, 制御系全体の特性を支配することになる。乙れは，従 来の一般化最小分散適応制御系に拈いて，

$$
R\left(z^{-1}\right)=K\left(P\left(z^{-1}\right) B\left(z^{-1}\right)+Q\left(z^{-1}\right) A\left(z^{-1}\right)\right)
$$

之定義した上で,

$$
H_{3}\left(z^{-1}\right)=\frac{R^{\prime}\left(z^{-1}\right)}{S^{\prime}\left(z^{-1}\right)}
$$

の補償器を直列に挿入した制御系に等価である。ここ で，(23)式におけるKは，定常偏差が生じないよう に,

$$
K=1 / B(1)
$$

とし，実際の計算では，後で示す逐次最小 2 乗法によ る推定結果に基づいて， $K$ の決定を順次行う. 以下 に, $H_{3}\left(z^{-1}\right)$ の設計法について考察する.

(1) 2 次系伝達関数に基づく設計

簡単な一例として, 次式に示す連続時間 2 次系伝達 関数 ${ }^{15)}$ を考える.

$$
G_{1}(s)=\frac{\omega_{n}^{2}}{s^{2}+2 \zeta \omega_{n} s+\omega_{n}^{2}}
$$

ここで, 希望する設計仕様に従って, 減衰係数らおよ び固有振動数 $\omega_{n}$ を決定する.さらに，この(32)式に 示す伝達関数 $G_{1}(s)$ を, サンプリング間隔 $T$ で離散 化し, $H_{3}\left(z^{-1}\right)$ を得る.

(2) 3 次系伝達関数に基づく設計

Exact Model Maching 手法において用いられる 連続時間 3 次系の希望伝達関数 ${ }^{155}$ 亿基づいて設計を行 う. 伝達関数 $G_{2}(s)$ は, 次式として与えられる.

$$
G_{2}(s)=\frac{\left(-\lambda_{k}\right) \omega_{n}^{2}}{-\sigma}-\frac{S-\sigma}{\left(s^{2}+2 \zeta \omega_{n} s+\omega_{n}^{2}\right)\left(s-\lambda_{k}\right)}
$$

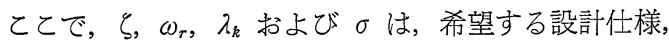
たとえば，パーセントオーバシュート量 $(P O)$, 遅れ 時間 $\left(t_{d}\right)$, バンド幅 $(B W)$ および定常速度偏差定数 $\left(K_{v}\right)$ などから決定する，その上で，(33)式に示す希 望伝達関数を，サンプリング間隔 $T$ で離散化する．乙 れにより, $H_{3}\left(z^{-1}\right)$ を得る.

以上により, 局所フィードバック補償器と前置補償 器の伝達関数を, 独立に設計できる一般化最小分散適 応制御系を構成するととができる，なお，システムの パラメータ $A\left(z^{-1}\right), B\left(z^{-1}\right)$ および $C\left(z^{-1}\right)$ は，以下に 示す逐次最小 2 乗法により推定を行う.

$$
\left.\begin{array}{l}
\hat{\theta}(t)=\hat{\theta}(t-1)+K(t) \varepsilon(t) \\
K(t)=\frac{p(t-1) \psi(t-k)}{1+\phi^{T}(t-k) p(t-1) \psi(t-k)} \\
P(t)=p(t-1)-\frac{p(t-1) \psi^{T}(t-k) \psi(t-k) p(t-1)}{1+\phi^{T}(t-k) p(t-1) \psi(t-k)} \\
\varepsilon(t)=y(t)-\hat{\theta}^{T}(t-1) \psi(t-k)
\end{array}\right\}
$$

ただし，

$$
\begin{aligned}
\hat{\theta}(t)=[ & \hat{a}_{1}(t), \hat{a}_{2}(t), \cdots, \hat{a}_{n}(t), \hat{b}_{0}(t), \hat{b}_{1}(t), \cdots, \hat{b}_{m}(t), \\
\hat{c}_{1}(t), & \left.\hat{c}_{2}(t), \cdots, \hat{c}_{l}(t)\right]^{T} \\
\psi(t-k)= & {[-y(t-1),-y(t-2), \cdots,} \\
& -y(t-n), u(t-k), u(t-k-1), \cdots, \\
& u(t-k-m), \varepsilon(t-1), \varepsilon(t-2), \cdots, \\
& \varepsilon(t-l)]^{T}
\end{aligned}
$$

次章では, 考察した制御アルゴリズムの有効性を数 值計算により，定量的に検証する。

\section{4. 数值計算結果}

伝達関数が，次式として示される連続系を考える.

$$
G(s)=\frac{1}{(s+1)(s+2)} e^{-0.2 s}
$$

これを，サンプリング間隔 $T=0.5$ で離散化すると， パルス伝達関数 $G^{*}\left(z^{-1}\right)$ は, 次式となる.

$$
G^{*}\left(z^{-1}\right)=\frac{z^{-1}\left(0.154+0.371 z^{-1}+0.021 z^{-2}\right)}{2\left(1-0.503 z^{-1}+0.053 z^{-2}\right)}
$$

したがって, 対象とする離散時間系は, 次式として示 される.

$$
\begin{aligned}
y(t)= & 0.503 y(t-1)-0.053 y(t-2)+0.077 u(t-1) \\
& +0.186 u(t-2)+0.011 u(t-3)+\xi(t)
\end{aligned}
$$

ただし， $E[\xi(t)]=0, E\left[\xi^{2}(t)\right]=0.01$ とする.この 之き, 出現する零点は, $z=-0.06,-2.34$ であり, 後者は不安定零点である.したがって，(37)式で記述 された離散時間系は，非最小位相系になっており， STC や MRACS をそのまま適用することは，不可 能である. 
(37)式に記述されるシステムに対し，Clarke らに よる従来の一般化最小分散適応制御による計算結果を Fig. 3 に示す. ここで，構成される制御系の特性方 程式は，(17)式と同様であり，Allidina らが考察し たように，乙の閉ループ系の極を， -0.3 と -0.5 に 指定し, $\operatorname{deg} P\left(z^{-1}\right)=n-1=1, \quad \operatorname{deg} Q\left(z^{-1}\right)=m-1=1$ を考慮して $P\left(z^{-1}\right)$ および $Q\left(z^{-1}\right)$ を設計した．規準 元力 $\omega(t)$ は，図中に一点鎖線で示す矩形波とする.

つぎに，本論文で考察した前置補償器の設計に基づ いた二般化最小分散適応制御アルゴリズムを適用す る。まず，2 次系希望伝達関数に基づいた設計法によ る制御結果について考察する。(32)式において，でき るだけオーバシュートを抑えるという目的から，ら= $1.5, \omega_{n}=5.0$ と設定 ${ }^{15)}$ し， サンプリング間隔 $T=0.5$ で離散化する。このとき，

$$
y_{c}(t)=H_{3}\left(z^{-1}\right) w(t)
$$

としたときの $y_{c}(t)$ を，Fig. 4 に示す.さらに，閉 ループ系の特性根を先に同様に， -0.3 および -0.5

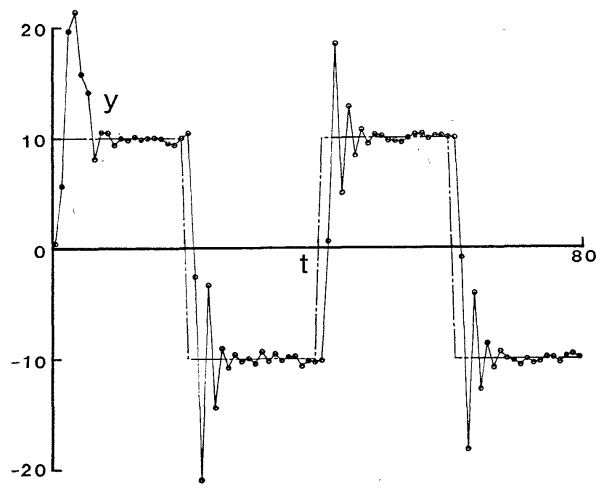

Fig. 3 Simulation result by the usual generalized minimum variance control with pole assignment

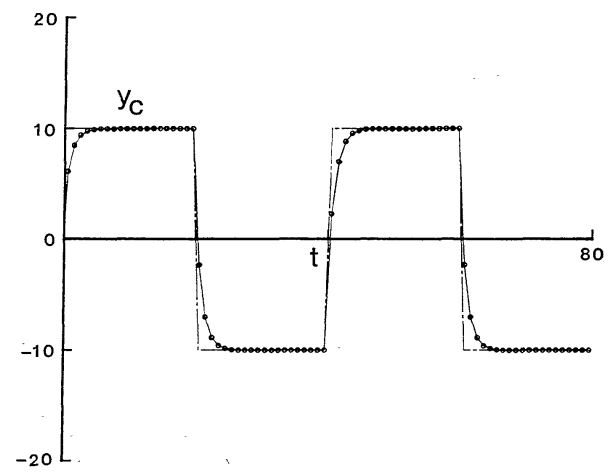

Fig. 4 The output result of $y_{c}(t)$ for the secondorder case
に指定し，制御を行った結果を，Fig. 5 亿示す.

Fig. 3 と比較して, オーバシュートも抑えられ，ま た $y(t)$ が $y_{c}(t)$ に，十分追従していることがわかる. つぎに，3 次系希望伝達関数に基づいた設計法によ る制御結果について考察する。ここで, 希望する設計 仕様を, $\mathrm{PO}=8[\%], t_{d} \leqq 0.001[\mathrm{~s}], K_{v} \geqq 10[\mathrm{rad} /$ s] とし，BW については設定しなかった. これによ り, 文献 15) に示す図加ら， $\zeta=0.707, \omega_{n}=10, \lambda_{k}=$ -60 および $\sigma=-22$ と定めた. さらに，乙れをサン プリング間隔 $T=0.5$ で離散化し， $H_{3}\left(z^{-1}\right)$ を得る.

このときの $y_{c}(t)$ を, Fig. 6 に示す. また，乙てで あ閉ループ系の特性根をー 0.3 および -0.5 に指定す る. このときの制御結果を, Fig. 7 亿示す. Fig. 8 には，システムのパラメータ同定結果を示す. Fig. 7 から，十分に $y_{c}(t)$ に追従する良好な制御結果が得ら れていることがわかる. Fig. 8 亿示すパラメータ同 定結果については， $a_{1}$ の推定結果が少し悪いものの, ほとんど真值に追従していることがわかる，また，規

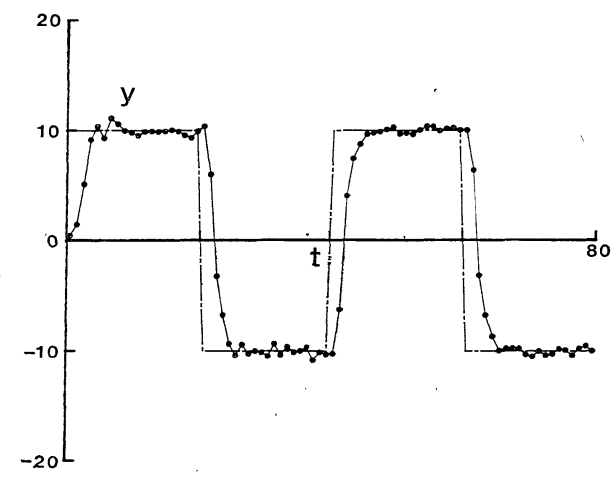

Fig. 5 Simulation result by the proposed generalized minimum variance control for the secondorder case

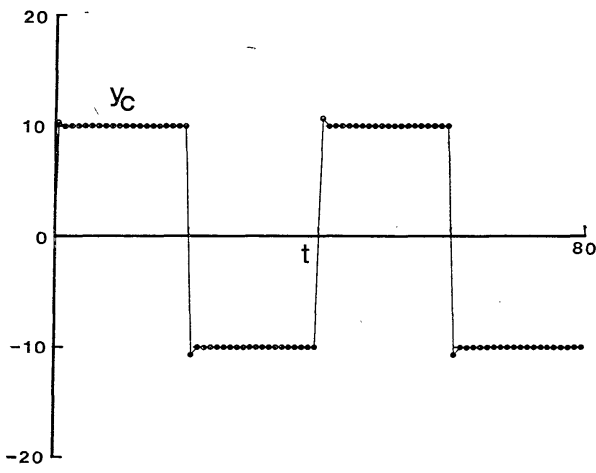

Fig. 6 The output result of $y_{c}(t)$ for the thirdorder case 


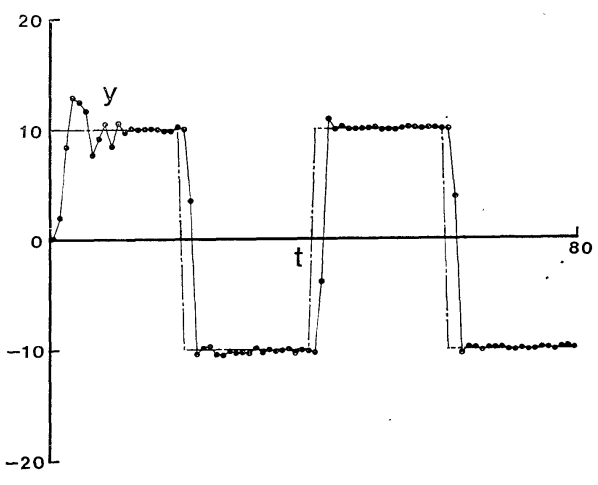

Fig. 7 Simulation result by the proposed generalized minimum variance control for the third-order case

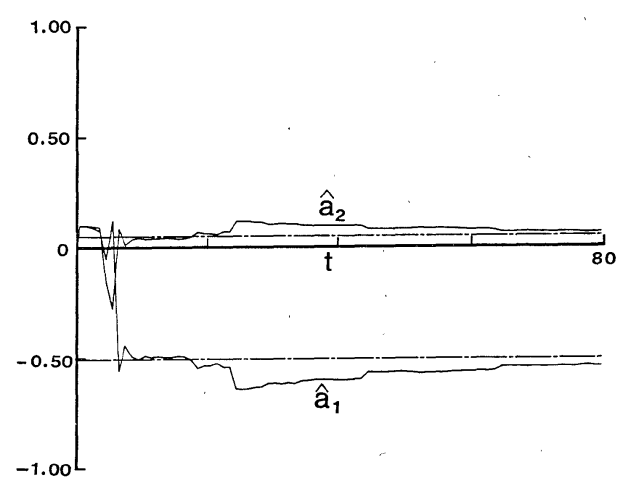

(a)

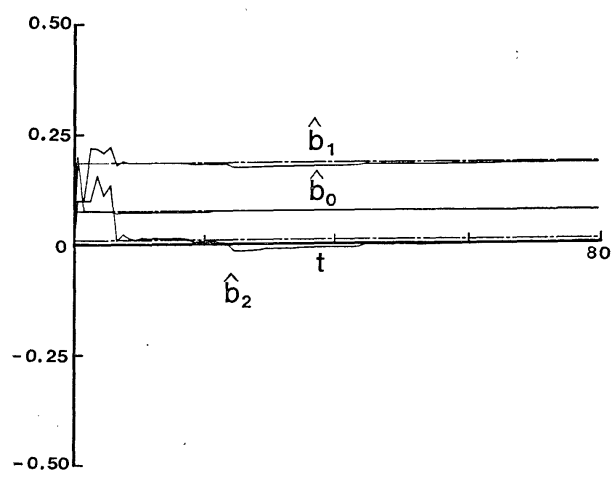

(b)

Fig. 8 The result of identified parameters in $A\left(z^{-1}\right)$ and $B\left(z^{-1}\right)$ by the recursive least squares method where -.- denotes true values

準入力が変化する度に，推定結果が修正されようとす る傾向がみられる.

以上により, 本論文で考察した前置補償器の設計に 基づいた一般化最小分散適応制御アルゴリズムの有効
性が，検証される。

\section{5. 結 言}

本論文では，Clarke らによる一般化最小分散適応 制御系 ${ }^{4), 5}$ が, 局所フィードバック補償器と前置補償 器を挿入した制御系になっているととを明確にした。 さらに，乙の局所フィードバック補償器と前置補償器 の伝達関数を設計する際, 従来の Clarke らによる方 法では，これらを独立に設計することは難しいととを 示した．そこで，新しい重み多項式を導入し，評価規 範を組み換えるととで, 独立に望ましい伝達関数を構 成するととが可能な一般化最小分散適応制御アルゴリ ズムについて考察した．てのとき, 前置補償器の設計 においては，2 次系抒よび 3 次系の希望伝達関数に基 づいた方法について考察した．最後に，数值計算によ り，本論文で考察した制御アルゴリズムの有効性を検 証した。

\section{参 考 文 献}

1) K. J. Åström, et al.: Zero of Sampled Systems, Automatica, 20-1, 31/38 (1984)

2) K. J. Åström, et al.: Theory and Applications of Self-Tuning Regulators, Automatica, 13-5, 457/476 (1977)

3) K. J. Åström: Theory and Applications of Adaptive Control-a Survey, Automatica, 19-5, 471/486 )1983)

4) D. W. Clarke and P. J. Gawthrop: Self-Tuning Controller, Proc. IEE, 123-9, 929/934 (1975)

5) D. W. Clarke: Self-Tuning Control of Nonminimum-Phase Systems, Automatica, 20-5, 501/517 (1984)

6) K. J. Åström and B. Wittenmark: On Self-Tuning Regulators, Automatica, 9, 185/199 (1973)

7) D.W. Clarke, et al.: Self-Tuning Control, Proc. IEE, 126-6, 633/639 (1979)

8) A. Y. Allidina and F. M. Hughes: Generalized SelfTuning Controller with Pole Assignment, Proc. IEE, 127-1, 13/18 (1980)

9）鈴木，新中，田中：適応極配置系の一構成法，計測自動 制御学会論文集, 19-1，28/35（1983）

10）新中，鈴木：適応極配置系汇関する一考察，計測自動制 御学会論文集，22-4，102/104（1986)

11）山本，渡辺，大松：非最小位相系に対する 2 次規範制御 の規準値追従性の改善，システムと制御，31-8，604/612 (1987)

12）山本, 大松, 石原：規準值追従性の改善 STC アルゴリ ズムに対する誤差解析，システムと制御，32-3，207/208 (1988)

13）山本，大松，石原：一般化最小分散適応制御比る圧力 タンクの圧力制御，日本機械学会論文集C 編，56-523, $731 / 737(1990)$

14）山本，石原，大松：一般化最小分散適応制御系の構成に 関する一考察，第 32 回自動制御連合講演会前刷，31/32 (1989)

15）市川邦彦：最新自動制御講義，学献社 (1983) 